University of Nebraska - Lincoln

DigitalCommons@University of Nebraska - Lincoln

1980

The Comparison of Usage and Availability Measurements for Evaluating Resource Preference

Douglas H. Johnson

USGS Northern Prairie Wildlife Research Center, Douglas_H_Johnson@usgs.gov

Follow this and additional works at: https://digitalcommons.unl.edu/usgsnpwrc

Part of the Other International and Area Studies Commons

Johnson, Douglas H., "The Comparison of Usage and Availability Measurements for Evaluating Resource Preference" (1980). USGS Northern Prairie Wildlife Research Center. 198.

https://digitalcommons.unl.edu/usgsnpwrc/198

This Article is brought to you for free and open access by the US Geological Survey at DigitalCommons@University of Nebraska - Lincoln. It has been accepted for inclusion in USGS Northern Prairie Wildlife Research Center by an authorized administrator of DigitalCommons@University of Nebraska - Lincoln. 


\title{
THE COMPARISON OF USAGE AND AVAILABILITY MEASUREMENTS FOR EVALUATING RESOURCE PREFERENCE ${ }^{1}$
}

\author{
Douglas H. Johnson \\ United States Fish and Wildlife Service, Northern Prairie Wildlife Research Center, \\ Jamestown, North Dakota 58401 USA
}

\begin{abstract}
Modern ecological research often involves the comparison of the usage of habitat types or food items to the availability of those resources to the animal. Widely used methods of determining preference from measurements of usage and availability depend critically on the array of components that the researcher, often with a degree of arbitrariness, deems available to the animal. This paper proposes a new method, based on ranks of components by usage and by availability. A virtue of the rank procedure is that it provides comparable results whether a questionable component is included or excluded from consideration. Statistical tests of significance are given for the method.

The paper also offers a hierarchical ordering of selection processes. This hierarchy resolves certain inconsistencies among studies of selection and is compatible with the analytic technique offered in the paper.

Key words: availability; food habits; habitat selection; preference; resource utilization; selection; usage.
\end{abstract}

\section{INTRODUCTION}

Central to the study of animal ecology is the usage an animal makes of its environment: specifically, the kinds of foods it consumes and the varieties of habitats it occupies. Many analytic procedures have been devised to treat data on the usage of such resources, particularly in relation to information on their availability to the animal, for the purpose of determining "preference." The objectives of this report are to describe the problem of determining preference by comparing usage and availability data, to illustrate a serious shortcoming in the routine application of most procedures for comparing these data, and to suggest a new method that resolves this difficulty. The proposed technique results in a ranking of the components on the basis of preference, and permits significance tests of the ranking.

Many investigators who use analytic procedures to handle usage and availability data fail to recognize the conditional nature of inferences drawn by comparing usage to availability. Conclusions about whether an individual component is used above, in proportion to, or below its availability are critically dependent upon the array of components the investigator deems available to the animal. This decision is often made somewhat arbitrarily by the investigator. The following contrived example will illustrate the point.

Suppose an investigator collects a fish, and finds that its stomach contains food items A, B and C in the percentages shown in Table 1(A) under "Usage." A sample of the animal's feeding site at the time the fish was collected reveals that the items were present in

\footnotetext{
${ }^{1}$ Manuscript received 23 May 1978; revised 1 May 1979; accepted 8 May 1979.
}

the proportions shown under "Availability." Many investigators would conclude that Item A is avoided, because usage was less than availability, while Items $B$ and $C$ are preferred, because usage exceeded availability. But suppose another investigator, equally familiar with the biology of the fish, does not believe that Item A is a valid food item (perhaps he thinks it is ingested only accidentally while the animal is consuming other foods). He would then consider the data in Table 1(B), obtained by deleting Item A from the analysis. Now, although Item $C$ is still deemed preferred, the assessment of Item B has changed from preferred to avoided.

Conclusions are not apt to be drawn from one fish, but whatever conclusions are reached about the preference or avoidance of any particular component of the environment depend markedly upon the array of components deemed by the investigator to be available to the animal. To the extent that the decision is arbitrary, so will be the conclusions drawn from the analysis. This inconsistency can result from the use of any of the standard methods, e.g., the forage ratio (Williams and Marshall 1938, Hess and Rainwater 1939), its modifications (Jacobs 1974, Chesson 1978), the index of electivity (Ivlev 1961), the difference (Swanson et al. 1974, Gilmer et al. 1975), or contingency tables (Hanson and Labisky 1964, Buchler 1976). Some authors have recognized the difficulty. Bartonek and Hickey (1969) noted that their decision to measure only items they considered as potential foods was subjective. Sugden $(1973: 28-29)$ mentioned that "the presence of other items will influence the rating for a given item. When the available food includes mostly unimportant items measured in the habitat, other items will be given a higher rating." Certain other authors 
TABLE 1. Example illustrating results of comparing usage and availability data when a common but seldom-used item is included 1(A) and when excluded 1(B) from consideration.

\begin{tabular}{|c|c|c|c|c|c|c|}
\hline \multirow[b]{2}{*}{ Item } & \multirow{2}{*}{$\begin{array}{l}\text { Usage } \\
(\%)\end{array}$} & \multirow{2}{*}{$\begin{array}{c}\text { Availability } \\
(\%)\end{array}$} & \multirow[b]{2}{*}{ Conclusion } & \multicolumn{3}{|c|}{ Rank } \\
\hline & & & & Usage & Availability & Difference \\
\hline \multicolumn{7}{|c|}{ (A) } \\
\hline A & 2 & 60 & Avoided & 3 & 1 & +2 \\
\hline B & 43 & 30 & Preferred & 2 & 2 & 0 \\
\hline $\mathrm{C}$ & 55 & 10 & Preferred & 1 & 3 & -2 \\
\hline \multicolumn{7}{|c|}{ (B) } \\
\hline B & 44 & 75 & Avoided & 2 & 1 & +1 \\
\hline $\mathrm{C}$ & 56 & 25 & Preferred & 1 & 2 & -1 \\
\hline
\end{tabular}

(e.g., Ivlev 1961, Chamrad and Box 1968) have been circumspect about interpreting usage-availability data, but many others (e.g. Hess and Swartz 1940, Bellrose and Anderson 1943, Jones 1952, Van Dyne and Heady 1965) have termed a component "preferred" if its usage exceeded its availability, and "avoided" if the reverse was true.

For the sequel, we define the following terms: The abundance of a component is the quantity of that component in the environment, as defined independently of the consumer. The availability of that component is its accessibility to the consumer. The usage of a component by the consumer is the quantity of that component utilized by the consumer in a fixed period of time. The selection of a component is a process in which an animal actually chooses that component. Usage is said to be selective if components are used disproportionately to their availability. The preference of a consumer for a particular component is a reflection of the likelihood of that component being chosen if offered on an equal basis with others. In theory, components can be ranked from "most preferred" to "least preferred." Preference is ordinarily claimed to be independent of availability, but is generally defined by reference to the choice made at equal availabilities (e.g., Pirnie 1935, Ellis et al. 1976).

\section{A Proposed Method}

The method that I suggest for analyzing usage-availability data yields rankings of items by preference with the following properties: (1) significance tests can be made for differences in preference among items; and more important, (2) the method gives largely comparable results whether the analysis includes or excludes doubtful items.

As a measure of preference, I propose using the difference between the rank of usage and the rank of availability. Call this difference $t_{i j}$, where $i$ indexes the component and $j$ indexes the individual animal. The differences can be averaged across animals, to obtain a mean for the $i^{\text {th }}$ component. Averages for different components can then be compared to deter- mine which are more preferred. If components are ordered by these average differences, the ranking will be from least preferred to most preferred.

Returning to the one-animal example previously considered, with Item A included, Table 1(A), the differences in the ranks of usage and availability are +2 , 0 , and -2 for Items A, B, and C, respectively. Should Item $\mathrm{A}$ be excluded from the analysis, Table 1(B), B and $C$ have values +1 and -1 , respectively. Although the values themselves change, the difference between $\mathrm{B}$ and $\mathrm{C}$ remains 2 , suggesting that $\mathrm{C}$ is preferred to $B$, regardless of whether A is included or excluded. We thus avoid absolute statements about preference.

Standard methods (e.g., forage ratio, Ivlev's index of electivity) can also be used to develop rankings in order of preference. Indeed, Ivlev (1961) recognized that preference values indicate only the relative value of a component in comparison to others, and Chesson (1978) did likewise. But many authors go much further and make absolute statements about preference and avoidance. The proposed method discourages this by using ranks, which by their nature represent relative values.

Furthermore, the loss of information resulting from the use of ranks of usage and availability, instead of the measured values, is of less consequence than might be supposed (Lehmann 1975). First of all, statistical methods based on ranks are nearly as efficient as methods based on the original data even when all the assumptions necessary to treat the original data hold (e.g., measurements are exact, their distribution is normal). Moreover, if the assumptions are not met, the rank methods have considerable advantages of efficiency and validity. And we have good reason to doubt the strict propriety of availability measurements. Sampling procedures used to determine availability values for the various components may not faithfully reflect the true availabilities to the animal under study (Savage 1931, Landenberger 1968, Bartonek and Hickey 1969, Sugden 1973, and Mitchell 1975). Thus, availability values are measured inexactly and methods based on ranks are to be preferred. 


\section{General formulation}

Let $X_{i j}$ be some measure of usage of component $i$ by individual $j$, and $Y_{i j}$ be a measure of the availability of component $i$ to individual $j$, where $i=1,2, \ldots$, $I(I=$ number of components) and $j=1,2, \ldots$, $J$ ( $J=$ number of individuals $)$. The values need not be scaled to be percentages. Take $r_{i j}$ to be the rank of $X_{i j}$ within $j$ (animal) and $s_{i j}$ the rank of $Y_{i j}$ within $j$. The difference in these ranks, $t_{i j}=r_{i j}-s_{i j}$, is a measure of preference for component $i$ by individual $j$.

It is a simple step to average the $t_{i j}$ across individuals, obtaining $\bar{t}_{i}=J^{-1} \sum_{j=1}^{J} t_{i j}$. A ranking of components in order of increasing $\bar{t}_{i}$ will then indicate the relative preference of the components by the entire sample of animals.

To draw statistical conclusions about the differences among components, we invoke the following model:

$$
t_{i j}=\mu+\alpha_{i}+\beta_{j}+\epsilon_{i j}
$$

where

$\mu$ is the overall mean,

$\alpha_{i}$ is the effect due to component $i(i=1, \ldots, I)$,

$\beta_{j}$ is the effect due to animal $j(j=1, \ldots, J)$,

$\epsilon_{i, j}$ is the random error term, and

$\sum_{i} \alpha_{i}=\sum_{j} \beta_{j}=0$

Because the $t_{i j}$ 's are differences in ranks within individuals, they sum to zero across $i$ :

$$
\sum_{i=1}^{l} t_{i j}=0 \text { for all } j,
$$

which implies $\mu=0, \beta_{j}=0$, and $\sum_{i=1}^{I} \epsilon_{i j}=0$, all $j$.

Thus the model (1) reduces to

$$
t_{i j}=\alpha_{i}+\epsilon_{i j} .
$$

Interest lies in the null hypothesis that

$$
\alpha_{1}=\ldots=\alpha_{I}(=0),
$$

that is, all components are equally preferred. Should that hypothesis be rejected in favor of the alternative that some components are more preferred than others, we would then wish to know which of the components are preferred to which others (the problem of multiple comparisons).

The distributional properties of our statistic are needed to test the null hypothesis. The average $\bar{t}_{i}$ equals the difference in the averages of the ranks:

$$
\bar{t}_{i}=\bar{r}_{i}-\bar{s}_{i} \text {. }
$$

It can be shown (e.g., by the method of Haigh 1971) that under general conditions $\bar{r}_{i}$ and $\bar{s}_{i}$ are normally distributed in large samples. Thus, their difference is also asymptotically normal, which allows us to employ the heavy statistical artillery developed for normal variables.

We assume the error terms $\left[\epsilon_{i j}\right]$ are distributed with zero mean, and independently between animals. Within an animal, however, error terms are (slightly) correlated (they sum to zero by Eq. 3), so standard analysis of variance techniques are inappropriate. A procedure that allows for correlations of error terms within animals is Hotelling's $T^{2}$ (e.g., Anderson 1958), which is used to test the hypothesis that a multivariate normal vector of means is equal to a specified vector (in the present case, a vector of zeroes).

Let

$$
v_{i k}=(J-1)^{-1} \sum_{j=1}^{J}\left(t_{i j}-\bar{t}_{i}\right)\left(t_{k j}-\bar{t}_{k}\right)
$$

be the covariance between components $i$ and $k$. (A computational note: Because of Eq. 2, the variancecovariance matrix for all components is singular. The following calculations are made by deleting one component from the analysis. The same answer ensues regardless of which component is deleted.) Let $V$ be the $(I-1) \times(I-1)$ covariance matrix, $V=\left[v_{i k}\right]$. Then the statistic

$$
F=\frac{J(J-I+1)}{(J-1)(I-1)} \sum_{i=1}^{I-1} \sum_{k=1}^{I-1} \bar{t}_{i} \bar{t}_{k} u_{i k},
$$

where $u_{i k}$ is the designated element of the inverse matrix of $V$ and $U=\left[u_{i k}\right]=V^{-1}$, is distributed under the null hypothesis (Eq. 4) as Snedecor's $F$ with $I$ 1 and $J-I+1$ degrees of freedom.

Should the calculated statistic be larger than the tabled $F$ value at some assigned significance level, the investigator will likely be interested in finding the source of the heterogeneity among the $\alpha$ 's. This is the multiple comparisons problem, which has been attacked by a number of procedures. (See review by O'Neill and Wetherill 1971.) In the example that follows, I chose to use the Bayesian decision procedure developed by Waller and Duncan (1969). It is rather simple to apply, solves the dilemma of whether to use experimentwise or comparisonwise error rates, and has performed nicely in comparative studies (Carmer and Swanson 1973).

Waller and Duncan suggested declaring significant a difference between two means if the difference exceeds $W S_{d}$, where $S_{d}$ is the standard error of the difference and $W$ is a function of the number of means under comparison (in our case $I-1$ ), the degrees of freedom $(J-I+1)$, and the $F$ statistic obtained earlier. The dependence of $W$ on $F$ is the characteristic feature of the Waller-Duncan method; its use reduces the chance of a Type I error by demanding a large 
TABLE 2. An example of wetland usage* and availability $\dagger$ data for 2 birds and 12 wetland classes.

\begin{tabular}{|c|c|c|c|c|c|c|c|c|}
\hline \multirow[b]{3}{*}{ Wetland class } & \multicolumn{4}{|c|}{ Measured values } & \multicolumn{4}{|c|}{ Rank } \\
\hline & \multicolumn{2}{|c|}{ Bird 5198} & \multicolumn{2}{|c|}{ Bird 5205} & \multicolumn{2}{|c|}{ Bird 5198} & \multicolumn{2}{|c|}{ Bird 5205} \\
\hline & Usage & $\begin{array}{l}\text { Avail- } \\
\text { ability }\end{array}$ & Usage & $\begin{array}{l}\text { Avail- } \\
\text { ability }\end{array}$ & Usage & $\begin{array}{l}\text { Avail- } \\
\text { ability }\end{array}$ & Usage & $\begin{array}{l}\text { Avail- } \\
\text { ability }\end{array}$ \\
\hline $1 / 2$ & 0.0 & 0.1 & 0.0 & 0.4 & 10.5 & 11 & 9.5 & 12 \\
\hline $3 / 8$ & 10.7 & 1.2 & 0.0 & 1.4 & 4 & 7 & 9.5 & 6 \\
\hline 9 & 4.7 & 2.9 & 21.0 & 3.5 & 6 & 5 & 2 & 4 \\
\hline 10 & 20.1 & 0.8 & 0.0 & 0.4 & 3 & 9 & 9.5 & 11 \\
\hline $11 / 14$ & 22.1 & 20.1 & 5.3 & 1.2 & 2 & 2 & 6 & 7.5 \\
\hline 15 & 0.0 & 1.4 & 10.5 & 4.9 & 10.5 & 6 & 4.5 & 3 \\
\hline $17 / 20$ & 2.7 & 12.6 & 0.0 & 1.0 & 7.5 & 3 & 9.5 & 9 \\
\hline $31 / 34$ & 29.5 & 4.7 & 15.8 & 5.1 & 1 & 4 & 3 & 2 \\
\hline 35 & 0.0 & 0.0 & 10.5 & 0.7 & 10.5 & 12 & 4.5 & 10 \\
\hline $36 / 38$ & 2.7 & 0.2 & 36.8 & 1.8 & 7.5 & 10 & 1 & 5 \\
\hline 39 & 7.4 & 1.1 & 0.0 & 1.2 & 5 & 8 & 9.5 & 7.5 \\
\hline Open & 0.0 & 54.9 & 0.0 & 78.3 & 10.5 & 1 & 9.5 & 1 \\
\hline Total & 99.9 & 100.0 & 99.9 & 99.9 & & & & \\
\hline
\end{tabular}

* Usage $=$ percentage of recorded locations in each wetland class.

$\dagger$ Availability = percentage of wetland area in a bird's home range in each wetland class.

difference if $F$ is small, and reduces the chance of a Type II error by requiring a less marked difference if $F$ is large.

\section{Application to real data}

The procedure described above is illustrated by some habitat usage and availability data collected by Gilmer et al. (1975). Data for 2 of their 24 radio-marked adult Mallards (Anas platyrhynchos) are displayed in Table 2. For each bird, a measure of usage is the percentage of locations recorded in each of 12 wetland classes, including "open water." (For this example, certain of the wetland classes used by Gilmer et al. have been combined.) Availability is taken to be the percentage of a wetland area in an individual bird's home range constituted by each wetland class. Interest lies in determining which classes of wetlands are favored, in the sense of receiving more intensive use by the Mallards.

It is apparent (Table 2) that the availability of open water far surpasses its usage. For this reason, usage of the other classes tends to exceed availability, which would suggest, if caveats about absolute statements were disregarded, that most of the other wetland classes were "preferred," whereas open water was avoided. In fact, in their original analysis, Gilmer et al. (1975) excluded most of the available open water from consideration. It is readily seen that the question of inclusion/exclusion is germane in this application.

To apply the new procedure, we first take the ranks of usage and availability values within each bird. Ranks for the two birds are shown in Table 2, where open water is included. (Results for "open water excluded" are not shown.) Next, for each bird, we take the difference between the rank of usage and the rank of availability. Averaging across all 24 birds in the complete sample yields the average differences shown in Table 3.

The hypothesis test outlined earlier yields the $F$-statistics $F=20.28(\mathrm{df}=11$ and 13$)$ when open water is included and $F=8.68$ ( $\mathrm{df}=10$ and 14$)$ when excluded. Both values are highly significant $(P<.001)$, leading us to reject the null hypothesis that all wetland classes are used with equal intensity. We now seek to determine the significant differences in preference among the wetland classes.

To declare a difference significant, it must exceed in absolute value $W S_{d}$, where $W$ is obtained from tables in Waller and Duncan (1969) and $S_{d}$ is the standard error of a difference between two means. For example, if $d=\bar{t}_{i}-\bar{t}_{k}$, then $s_{d}{ }^{2}=\operatorname{var}\left(\bar{t}_{i}\right)+\operatorname{var}\left(\bar{t}_{k}\right)$ $-2 \operatorname{cov}\left(\bar{t}_{i}, \bar{t}_{k}\right)$. To determine $W$ the investigator must select a value for $K$, the Type I to Type II error seriousness ratio. We use $K=100$, which Waller and

TABLE 3. Average differences between ranks of wetland class usage and the availability of that class.

\begin{tabular}{ccc}
\hline \hline & \multicolumn{2}{c}{ Average difference in ranks } \\
\cline { 2 - 3 } Wetland class & $\begin{array}{c}\text { Open water } \\
\text { included }\end{array}$ & $\begin{array}{c}\text { Open water } \\
\text { excluded }\end{array}$ \\
\hline $1 / 2$ & -2.44 & -1.94 \\
$3 / 8$ & -3.29 & -2.42 \\
9 & 1.50 & 2.02 \\
10 & -1.33 & -0.98 \\
$11 / 14$ & .52 & 1.31 \\
15 & 3.60 & 3.96 \\
$17 / 20$ & 2.94 & 3.35 \\
$31 / 34$ & -1.19 & -0.19 \\
35 & -2.88 & -2.38 \\
$36 / 38$ & -2.58 & -1.81 \\
39 & -1.54 & -0.94 \\
Open & 6.69 & - \\
\hline
\end{tabular}


Duncan concluded to be closely analogous to the usual Type I significance level of $P=.05$. Looking in Table A2 of Waller and Duncan, with 11 means under consideration, 13 error degrees of freedom, and $K=100$, we can interpolate for $F=20.28$ between the values for $F=10$ and $F=25$. The appropriate value is $W=$ 1.93. Thus, any difference $d=\bar{t}_{i}-\bar{t}_{k}$ between wetland classes $i$ and $k$ in the "open water included" portion of Table 3 is declared significant if

$$
\frac{|d|}{S_{d}}>1.93 \text {. }
$$

Following the same procedure for "open water excluded," we find the critical value to be 2.00 .

The wetland classes may then be ordered to sort out the significant differences. With open water included, we get

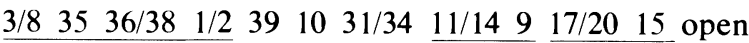

Wetland classes underscored by the same line are deemed not significantly different, while lack of a common underscore indicates that the habitat classes differ significantly. The results when open water is excluded are as follows:

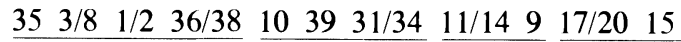

Notice particularly that the conclusions reached about the relative preference of each habitat are substantially similar in the two cases, a desirable feature of the method.

\section{Discussion}

It is clear that conclusions reached from usageavailability studies depend on the investigator's notion of what components are available to the animal. This dependency is more pervasive than it may first appear. In habitat studies, as an example, the usage of particular habitat types is compared with the availability of each type within the animal's home range, or perhaps within the study area defined by the investigator. But the very fact that the animal has its home range where it does, or that it occurs within the study area, is itself indicative that the animal has already made a selection. The analogous situation appears in feeding studies, where the presence of an animal at its feeding site suggests that it selected that site in part because of the food items available there. Comparing usage values to the availabilities within the home range, or at the feeding site, may well be misleading.

To recognize this hierarchical nature of selection, the concept of selection order can be introduced. A selection process will be of higher order than another if it is conditional upon the latter. As an example, selection of habitat types within a home range of an animal is of higher order than selection of the home range, because the availability of each habitat type is determined by the selection of the home range. Similarly, selection of food items is of higher order than selection of feeding site, for the site delimits the array of food items available to be selected.

A natural ordering of selection processes can be identified. First-order selection can be defined as the selection of physical or geographical range of a species. Within that range, second-order selection determines the home range of an individual or social group. Third-order selection pertains to the usage made of various habitat components within the home range. Finally, if third-order selection determines a feeding site, the actual procurement of food items from those available at that site can be termed fourth-order selection. Although it is no doubt possible to divide these selection orders more finely, those defined above should suffice for most applications.

The concept of selection order has been implicitly recognized in the ecological literature. Owen (1972) noted that "selection can be exercised at difference scales"; he contrasted selection of vegetative zones for feeding sites (third order) and selection within zones of plant species or parts of plants (fourth order). Wiens (1973) recognized different levels or scales of distributional patterns among breeding birds, and identified geographic range (first order), local site and plot patterns in territories (second order), and patterns of utilization (third order).

This hierarchy of selection has a unifying nature. Habitat usage studies and investigations of feeding are no longer qualitatively distinct; they are simply of different orders. The question of inclusion/exclusion of components also resolves itself in this context. The components available depend upon the order of selection being considered. Related to this, it is easy to avoid the fallacy of absolute claims, such as saying that a food item is avoided by an animal because only $50 \%$ of the animal's consumption consisted of that item, whereas it made up $90 \%$ of the items available at the feeding site. The animal may indeed have chosen that site because the item was abundant there. Absolute statements about preference or avoidance should be guarded against. Relative statements are possible because their nature invokes the concept of selection order.

The ranking approach has been used earlier, for example by Landenberger (1968), who found a hierarchy of preferences to be well defined and consistent among replicates. Consistency of preference rankings has also been found by investigators employing pairedchoice experimental designs (e.g., Thompson 1965, Mulkern 1967). A ranking of components is all that can be expected from an analysis of usage relative to availability. Indeed, a ranking may be all that is desired: many of the models developed in optimal foraging theory rely on rank orders of food types from most preferred to least preferred (e.g., Pyke et al. 1977). 
Another consideration is that preference is reflected in selection, which can occur only when the component is relatively scarce A component vital to the consumer may be so abundant that the consumer need only use small amounts of it to satisfy its requirements. Thus, usage is less than availability, but a conclusion that the component is of little value may not be warranted (Maitland 1965).

The method of comparing usage and availability data presented here possesses several desirable features. First, it places the components in order according to preference, an ordering consistent with the hierarchical selection model proposed herein. The method is relatively insensitive to the inclusion/exclusion of doubtful components. Results are less subjective, in the sense of being affected by possibly arbitrary decisions made by the investigator. Second, because the method employs the ranks of usage and availability measurements, these measures need not be estimated exactly or without bias. Finally, the method yields tests of significance, which permit statistical comparisons among the components.

A FORTRAN program to perform the calculations described in this report is available. ${ }^{2}$

\section{ACKNOWLEDGMENTS}

I am grateful to David S. Gilmer for providing the source data used in the example, to Ell-Piret Multer for bibliographic assistance, and to Alan B. Sargeant and Erik Fritzell for suggestions on the manuscript.

\section{Literature Cited}

Anderson, T. W. 1958. An introduction to multivariate statistical analysis. John Wiley and Sons, New York, New York, USA.

Bartonek, J. C., and J. J. Hickey. 1969. Selective feeding by juvenile diving ducks in summer. Auk 86:443-457.

Bellrose, F. C., Jr., and H. G. Anderson. 1943. Preferential rating of duck food plants. Illinois Natural History Survey Bulletin 22:417-433.

Buchler, E. R. 1976. Prey selection by Myotis lucifugus (Chiroptera: Vespertilionidae). American Naturalist 110:619-628.

Carmer, S. G., and M. R. Swanson. 1973. An evaluation of ten pairwise multiple comparison procedures by Monte Carlo methods. Journal of the American Statistical Association 68:66-74.

Chamrad, A. D., and T. W. Box. 1968. Food habits of whitetailed deer in south Texas. Journal of Range Management 21:158-164.

Chesson, J. 1978. Measuring preference in selective predation. Ecology 59:211-215.

Ellis, J. E., J. A. Wiens, C. F. Rodell, and J. C. Anway. 1976. A conceptual model of diet selection as an ecosystem process. Journal of Theoretical Biology 60:93-108.

2 See National Auxiliary Publications Service document \#03648 for 21 pages of supplementary material. For a copy of this document, contact the author or order from ASIS/ NAPS, Microfiche Publications, P.O. Box 3513, Grand Central Station, New York, New York 10017 USA.
Gilmer, D. S., I. J. Ball, L. M. Cowardin, J. H. Riechmann, and J. R. Tester. 1975. Habitat use and home range of mallards breeding in Minnesota. Journal of Wildlife Management 39:781-789.

Haigh, J. 1971. A neat way to prove asymptotic normality. Biometrika 58:677-678.

Hanson, W. R., and R. F. Labisky. 1964. Association of pheasants with vegetative types in east-central Illinois. Transactions of the North American Wildlife and Natural Resources Conference 29:295-306.

Hess, A. D., and J. H. Rainwater. 1939. A method for measuring the food preference of trout. Copeia 3:154-157.

Hess, A. D., and A. Swartz. 1940. The forage ratio and its use in determining the food grade of streams. Transactions of the North American Wildlife Conference 5:162-164.

Ivlev, V. S. 1961. Experimental ecology of the feeding of fishes. Yale University Press, New Haven, Connecticut, USA.

Jacobs, J. 1974. Quantitative measurement of food selection. Oecologia (Berlin) 14:413-417.

Jones, N. S. 1952. The bottom fauna and the food of flatfish off the Cumberland coast. Journal of Animal Ecology 21:182-205.

Landenberger, D. E. 1968. Studies on selective feeding in the Pacific starfish Pisaster in southern California. Ecology 49: 1062-1075.

Lehmann, E. L. 1975. Nonparametrics: statistical methods based on ranks. Holden-Day, San Francisco, California, USA.

Maitland, P. S. 1965. The feeding relationships of salmon, trout, minnows, stone loach and three-spined sticklebacks in the River Endrick, Scotland. Journal of Animal Ecology 34: 109-133.

Mitchell, J. E. 1975. Variation in food preferences of three grasshopper species (Acrididae: Orthoptera) as a function of food availability. American Midland Naturalist 94:267283.

Mulkern, G. B. 1967. Food selection by grasshoppers. Annual Review of Entomology 12:59-78.

O'Neill, R., and G. B. Wetherill. 1971. The present state of multiple comparison methods (with discussion). Journal of the Royal Statistical Society B33:218-250.

Owen, M. 1972. Some factors affecting food intake and selection in white-fronted geese. Journal of Animal Ecology 41:79-92.

Pirnie, M. D. 1935. Michigan waterfowl management. Michigan Department of Conservation, Lansing, Michigan, USA.

Pyke, G. H., H. R. Pulliam, and E. L. Charnov. 1977. Optimal foraging: a selective review of theory and tests. Quarterly Review of Biology 52:137-154.

Savage, R. E. 1931. The relation between the feeding of the herring off the east coast of England and the plankton of the surrounding waters. [Great Britain] Fishery Investigations Series, Number 2. Volume 12. Ministry of Agriculture and Fisheries, London, England.

Sugden, L. G. 1973. Feeding ecology of pintail, gadwall, American widgeon and lesser scaup ducklings in southern Alberta. Canadian Wildlife Service Report Series 24. Canadian Wildlife Service, Ottawa, Canada.

Swanson, G. A., M. I. Meyer, and J. R. Serie. 1974. Feeding ecology of breeding blue-winged teals. Journal of Wildlife Management 38:396-407.

Thompson, D. Q. 1965. Food preferences of the meadow vole (Microtus pennsylvanicus) in relation to habitat affinities. American Midland Naturalist 74:76-86.

Van Dyne, G. M., and H. F. Heady. 1965. Botanical composition of sheep and cattle diets on a mature annual range. Hilgardia 36:465-492. 
Waller, R. A., and D. B. Duncan. 1969. A Bayes rule for the symmetric multiple comparisons problem. Journal of the American Statistical Association 64:1484-1503.

Wiens, J. A. 1973. Pattern and process in grassland bird communities. Ecological Monographs 43:237-270.
Williams, C. S., and W. H. Marshall. 1938. Duck nesting studies, Bear River Migratory Bird Refuge, Utah, 1937. Journal of Wildlife Management 2:29-48. 